[5] H. Finkelstern. Multiples travaux, particulièrement dans la Zeitschrift für Kinderheilkunde, $\mathbf{4 9}$ et $\mathbf{5 0}$. Les idées de cet auteur sont exposées en langue française dans un article : La fièvre alimentaire (fièvre d'exsiccation), in Revue franৎaise de Pédiatrie, 1931, 7, 2, 161-174.

[6] Ch.-L. Goldbera. La fièvre de lait sec. Thèse de doctorat en médecine, Paris, 1931-32. (Bibliographie.)

[7] Hrrsch et Moro. Untersuchungen über alimentäres Fieber. Jahrb. f. Kind., 1917 et 1918.

[8] Laurensich. Sulle febbri alimentari. La Pediatria, 1928, 37, 5.

[9] P. Lereboullet. La fièvro de lait sec. Le Progrès médical, 25 juillet 1931.

[10] P. Lereboullet. Les fièvres alimentairos. Le Progrès médical, 8 août 1931.

[11] M. Lust, La fièvre de lait sec. Le Scalpel, 8 octobre 1927.

[12] Mathieu et Chabrun. La fièvre alimentaire en clinique. Congrès de Strasbourg, octobre 1931. (Bibliographie détaillée.)

[13] S. Paulon, Concentrazione ematica e rieambio idrico nell'infarizia. Rivista di Clinica pediatrica, décembre 1931, 12, 1115-1141.

[14] Ch. Porcher. Le lait desséché. Un volume de 298 pages. Lyon, 1926.

[15] H. Riesteoned. Multiples publications, parmi lesquelles il faut surtout citer : Alimentäres Fieber. Medizinische Klinik, 1927, 24 (Biliographie) ; Ueber alimentäres Fieber bei Säuglingen und Kleinkindern und seine Behandlung. Thérapie der Gegenwart, H. 5, 1928.

[16] G. SchaEFFER. Les essais d'interprétation physiologique des fièvres alimentaires du nourrisson. Congrès de Strasbourg, octobre 1931. (Bibliographie étendue.)

[17] Er. Schtfr. Das Exsiccoseproblem. Un volume de 85 pages, chez Springer, 1929. (Bibliographie détaillée.)

[18] W. Sormist. Weitere Untersuchungen über die Entstehung der dynamischen Eiweisshyperthermis. Archiv für experimentelle Pathologie und Pharmakologie, Bd. 10k, H. 1, 2, 1925.

[19] C. Sonrentino. Febbri alimentari o febbri da essicosi ? Rinascenza medica, 1931, 18, 19. Exposé succinct et clair des diverses théories émises, sur la fièvre de lait sec: thèses de Heim et John, Rietschet, Debré, FinKELSTEIs (Bibliographie complète.)

\title{
UNE NOUVELLE MÉTHODE DE DIFFÉRENCIATION BIOCHIMIQUE DES GROUPES COLI et AEROGENES (1)
}

\author{
par \\ CHR. BARTHEL. \\ Travail du Laboratoire bactériologique de la Station centrale \\ de Recherches agricoles a Experimentalfältet, Stockholm.
}

Les moyens biochimiques pour établir la différence entre le Bact. coli et le Bact. aerogenes sont assez nombreux. Il y a la réaction de Voges-Proskader, la réaction du rouge neutre, l'épreuve de l'indol

(1) Paru dans le Volume jubilaire du Professeur Ch. Porcher. 
et l'épreuve de Koser au eitrate de soude, et je ne nomme que celles qui sont les plus en usage et les plus sûres (1). Pourtant, il existe toujours des eas où la différenciation diagnostique devient plus ou moins douteuse, et chaque contribution à la précision du diagnostic est appelée à rendre des services, pourvu que la méthode en question soit suffisamment bonne pour donner des résultats nets qu'on puisse reproduire.

C'est à ce point de vue que je veux donner ici la description d'une nouvelle méthode de différenciation entre ces deux groupes de bactéries. Cette méthode repose sur le fait que les cultures en lait de Bact. aerogenes produisent des quantités notables des composés fixant l'iode, tandis que Bact. coli ne possède pas cette qualité.

C'est au cours des expériences exécutées il y a bien des années en collaboration avec M. ENGFELDT sur un certain nombre de microbes isolés du lait, au point de vue de leur production de corps fixant l'iode, que j'ai trouvé, en continuant ces recherches, qu'il existe une différence remarquable à ce point de vue entre les coli et les aerogenes. $J$ 'ai repris ces recherches dans le dernier temps et, quoique le nombre des expériences soit encore assez restreint, je crois utile d'en exposer ici quelques résultats, même s'il faut considérer cette note plutôt comme une communication préliminaire, vu qu'il faudra encore vérifier les résultats obtenus par des expériences exécutées sur un plus grand nombre de cultures.

Voici la façon dont j'ai opéré : 100 millilitres de lait frais entier sont introduits dans un ballon d'ERLENMEYER de 200 millilitres et stérilisés pendant 20 minutes à l'autoclave à $115^{\circ}$. On ensemence avec une anse de platine d'une culture en lait écrémé stérilisé, restée 24 heures à $37^{\circ}$. Le ballon est mis à l'étuve à $37^{\circ}$ et on y met en même temps un ballon-témoin, non ensemencé. Après quelques jours, au cours desquels on agite de temps en temps, on procède à l'analyse.

Dans un ballon de 500 millilitres, on mélange la culture avec 100 millilitres de l'eau distillée. Le ballon est réuni à un réfrigérant vertical, dont l'orifice est introduit dans le bouchon d'un flacon à succion dans lequel on a mis 50 millilitres d'eau distillée. La tubulure latérale de celui-ci est mise en communication avec un tube de PÉLIGOT, contenant 10 millilitres d'eau. On distille pendant 15 minutes exactement, on lave le tube réfrigérant avec l'eau du tube de PÉLIGot avant d'ôter le flacon de succion, après quoi on introduit le distillat avec 50 millilitres d'une solution décinormale d'iode et 10 millilitres d'une solution de $\mathrm{NaOH}$ à $25 \%$ dans un ballon d'ERLENMEYER, bouché à l'émeri. On laisse en repos pendant 15 minutes, et, après avoir acidifié avec de l'acide sulfurique étendu, on titre au moyen d'une solution décinor-

(1) Voir à ce sujet : Rughroft, Kalias, Chinn et Coulter. Journal of Bacter riology, 1931, 22, 125. 
male de thiosulfate de soude, en ajoutant, vers la fin de la titration, quelques gouttes d'une solution d'amidon fraîchement préparée. Le ballon avec le lait-témoin est traité exactement de la même façon et le chiffre obtenu est soustrait au chiffre total de la culture. La quantité d'iode fixé par la culture est ensuite exprimée en millilitres d'iode décinormale.

Pour le Bact. coli, ce chiffre reste toujours très peu supérieur au chiffre du témoin, qui généralement reste au-dessous de 1 , tandis que le Bact. aerogenes donne des chiffres bien plus élevés.

Dans le tableau I, on trouve quelques exemples des résultats obtenus avec des cultures en lait de Bact. coli et de Bact. aerogenes de provenances diverses. Les cultures étaient âgées de 10 jours (370).

Les coli étaient isolés des excréments de vache et d'homme. Les aerogenes provenaient des échantillons de lait, de la crème et de fromage boursouflé. Toutes ces souches se comportaient de façon typique aux épreuves de l'indol et de Voges-Proskaukr.

On peut aussi employer des cultures de 50 millilitres, pour économiser les solutions décinormales.

TABLEAU I.

\begin{tabular}{|c|c|c|c|}
\hline Gulture & Taux de fixation & d'iode & ? \\
\hline Coli $1 \ldots \ldots \ldots \ldots \ldots \ldots \ldots$ & 0,8 & & \\
\hline Coli $2, \ldots \ldots \ldots \ldots \ldots \ldots \ldots \ldots$ & 1,1 & s. & \\
\hline Coli $3 \ldots \ldots \ldots \ldots \ldots \ldots \ldots \ldots \ldots$ & 0,5 & & \\
\hline Coli $\mathrm{P}, \ldots \ldots \ldots \ldots \ldots \ldots \ldots \ldots \ldots \ldots$ & 0,7 & & $\therefore$ \\
\hline Aerogenes 1 & 29,0 & & \\
\hline Aerogenes $2, \ldots \ldots \ldots \ldots \ldots \ldots$ & 30,3 & & \\
\hline Aerogenes V2 $\ldots \ldots \ldots \ldots \ldots \ldots$ & 39,0 & & \\
\hline Aerogenes $04 \quad \ldots \ldots \ldots \ldots \ldots \ldots \ldots$ & 4,1 & & \\
\hline
\end{tabular}

Il ne faut pas s'attendre à trouver des chiffres constants, en analysant de la façon décrite plus haut des cultures de Bact. aerogenes de la même souche aux occasions différentes. Même entre des cultures parallèles, les différences peuvent être assez élevées. On en trouve des preuves dans le tableau II, qui démontre, d'autre part, l'augmentation des chiffres de la fixation d'iode avec le temps pendant lequel les cultures sont laissées à l'éture à $37^{\circ}$.

Le lait-témoin stérile avait un chiffre d'iode de 0,7 . Ce chiffre est partout soustrait aux taux ci-après. 
TABLEAU II.

Taux d'iode des cultures en lait $(100 \mathrm{ml})$ d'une même souche de Bact. aerogenes à $37^{\circ}$

\begin{tabular}{|c|c|c|c|c|c|}
\hline \multicolumn{2}{|c|}{2 jours } & 4 jours & 6 jours & 8 jours & 10 jours \\
\hline A. & 6,42 & 6,66 & 10,89 & 13,84 & 16,87 \\
\hline B. & 6,17 & 6,86 & 14,23 & 19,76 & 27,18 \\
\hline
\end{tabular}

On voit que les chiffres absolus ont très peu de valeur. Le principe de la méthode repose tout simplement sur le fait que les cultures en lait de Bact. aerogenes ont toujours un chiffre de fixation d'iode bien plus élevé que le témoin stérile, tandis que les chiffres des cultures de Bact. coli restent au voisinage de celui-ci.

Je ne peux pas encore me prononcer d'une façon définitive sur la nature des corps réagissant avec l'iode qui se forment dans les cultures en lait de Bact. aerogenes. Toutefois, comme ce microbe produit des quantités très notables d'acétylméthylcarbinol dans le lait, il est bien probable que ce corps entre aussi pour une large part dans la réaction avec l'iode.

La réaction de Voghs-Proskauer se base aussi sur la présence, dans du bouillon dextrosé, de l'acétylméthylearbinol. Notre réaction peut donc servir en quelque sorte comme contrôle de la réaction Voges-Proskader et devenir ainsi encore une preuve dans la différenciation parfois assez difficile entre Bact. coli et Bact. aerogenes.

\title{
L'ACIDIFICATION PROLONGÉE DU PETIT-LAIT (1)
}

\author{
par
}

\section{le Professeur Dr Otakar LAXA}

Directeur de l'Institut lactologique à l'Ecole polytechnique à Prague.

C'est une chose connue que l'acidification spontanée du petit-lait se fait plus lentement que celle du lait lui-même, phénomène qu'on peut expliquer par le manque de caséine, qui, dans le cas du lait, s'unit à une partie de l'acide lactique de telle manière que les bactéries ácidifiantes trouvent ainsi le liquide plus apte à la transformation du lactose. Et pourtant le petit-lait peut atteindre après une longue période, une acidité remarquable, comme le montre l'exemple suivant.

Une bouteille de 10 litres remplie jusqu'au bouchon de petit-

(1) Paru dans lo Volume jubilaire du Professeur Ch. Porcher. 